\title{
Impact strength and behavior of concrete containing different plastic wastes
}

\author{
Azad A. Mohammed \\ Civil Engineering Department, College of Engineering, University of Sulaimani, Sulaimani, Iraq, E-mail:
}

\begin{abstract}
.
The growth of post consumed plastic wastes requires recycling to save the environment against pollution. One solution is the reuse of the waste as a substantially material for concrete production. Different properties of concrete containing different plastic wastes have been investigated by the past researchers. In this study, impact strength and behavior of normal strength concrete contained shredded PVC waste aggregate or PET waste fiber has been investigated experimentally. Results show that there is a first crack impact and ultimate impact loads enhancement of $97 \%$ and $23 \%$ as a result of using $20 \mathrm{~mm}$ length PET fiber added to concrete by $0.75 \%$. The impact performance of $40 \mathrm{~mm}$ length PET fiber was found to be lower as compared with that of $20 \mathrm{~mm}$ length fiber to enhance impact. There is a reduction in both first crack impact and ultimate load impact of concrete as a result of replacing a part of fine aggregate with a PVC waste aggregate reaching $84 \%$ related to using $45 \%$ PVC aggregate as fine aggregate replacement. Results also show that there is a strong linear relationship between the first crack impact and ultimate load impact for concrete contained PET fiber or PVC aggregate.
\end{abstract}

Keywords: First crack, Impact strength, PET fiber, PVC aggregate

\section{Introduction}

Using different kinds of plastic polymers are in growth day by day mainly because these products are of low cost as compared with the other products such as metals. As a result, there is a huge post consuming wastes need to be managed to save the land and water resources against pollution [1]. There is a good chance to use the shredded plastic waste as an aggregate or especially cut to make a plastic fiber, to produce a recycled concrete [2]. Many properties of concrete containing different plastic wastes have been investigated by the past researchers $[2,3]$. In a recent review paper, fresh and hardened properties of concrete containing different forms of plastic waste have been investigated by Bahji et al. [4]. They concluded that, in general, workability of fresh concrete, compressive strength, splitting tensile strength and flexural strength are reduced as a result of using plastic aggregate in concrete. They also concluded that there is chance to improve different strengths of concrete as a result of using plastic fiber in concrete.

One of the most important structural properties of concrete is the impact strength. Impact loading acts on a structure mostly with a low probability of occurrence, but failure due to 


\section{$2^{\text {nd }}$ International Academic Conference on Research in}

\section{9-11 July 2021 \\ Paris, France}

impact loading is accompanied with a serious structural damage. Effect of impact loading is already seen in the case of repeated falling load in pile driving, explosives and earthquakes. For the mentioned cases and others, concrete structure must be designed for the impact resistance [5]. Impact strength and properties of different concrete were studied experimentally by many researchers. For instance, impact strength of normal strength concrete was studied by Zhu et al. [6]. Abhinav and Rao [7] worked on impact strength of normal concrete with steel fiber, and Kun [8] investigated impact properties of fiber reinforced high strength concrete. With regards concrete with plastic waste, a critical review of impact strength of concrete and testing for impact was made in a recent paper [9]. Parahallada and Prakash [10] tested concrete with plastic waste fiber. The optimum dosage of plastic addition was found to be $1 \%$ to enhance impact strength. First crack impact enhancement was between $75 \%$ and $80 \%$, while the ultimate load impact enhancement was between $142 \%$ and $145 \%$. Jain et al. [11] found that there is an impact enhancement of concrete contained plastic waste bag up to $20 \%$. Furthermore, AlHadithi et al. [12] reported that there is no appreciable positive effect of PET fiber addition to self-compacting concrete to enhance impact.

In this study, impact strength and behavior of two concrete mixture containing PET fiber and PVC aggregate have been investigated experimentally. The effects of PVC aggregate and PET fiber volume fractions and fiber length on the impact behavior were investigated. Test data are analyzed and compared and conclusions were drawn.

\section{Experimental works}

\subsection{Materials}

Materials used for normal strength concrete tested in this study were ordinary Portland cement (Type I), fine aggregate, coarse aggregate and water. Dry crushed gravel coarse aggregate of $12 \mathrm{~mm}$ maximum size, and saturated surface dry sand of coarse grading was used. For the sand used, dry compacted density was found to be $1777 \mathrm{~kg} / \mathrm{m}^{3}$. Besides, two types of plastic wastes were used, polyvinyl chloride (PVC) aggregate and polyethylene terephthalate (PET) fiber, to investigate the effect of these plastic additions on the impact strength of concrete. Two types of PET fiber with regard the length were used, one of $20 \mathrm{~mm}$ length, shown in Fig. 1, and the other of $40 \mathrm{~mm}$ length, shown in Fig. 2. Cross section of this plastic fiber was $1.2 \mathrm{~mm}$ by $0.4 \mathrm{~mm}$. This plastic fiber was cut manually from the $17 \mathrm{~L}$ capacity water drinking bottle. Specific gravity of PET fiber was found to be 1.21. Plastic aggregate obtained from shredding PVC waste sheets shown in Fig. 3 was used in concrete mixes as fine aggregate replacement. This plastic aggregate was obtained from PVC sheets used basically for covering walls and secondary roofs in buildings. The plastic aggregate was found to pass by $90 \%$ on the $4.75 \mathrm{~mm}$ sieve, and the dry density was $810 \mathrm{~kg} / \mathrm{m}^{3}$. 
사는

International Academic Conference On Research in
ENGINEERING and TECHNOLOGY $2^{\text {nd }}$ International Academic Conference on Research in ENGINEERING AND TECHNOLOGY

\section{9-11 July 2021}

\section{Paris, France}

Figure 1: PET waste fiber (20 $\mathrm{mm}$ length)
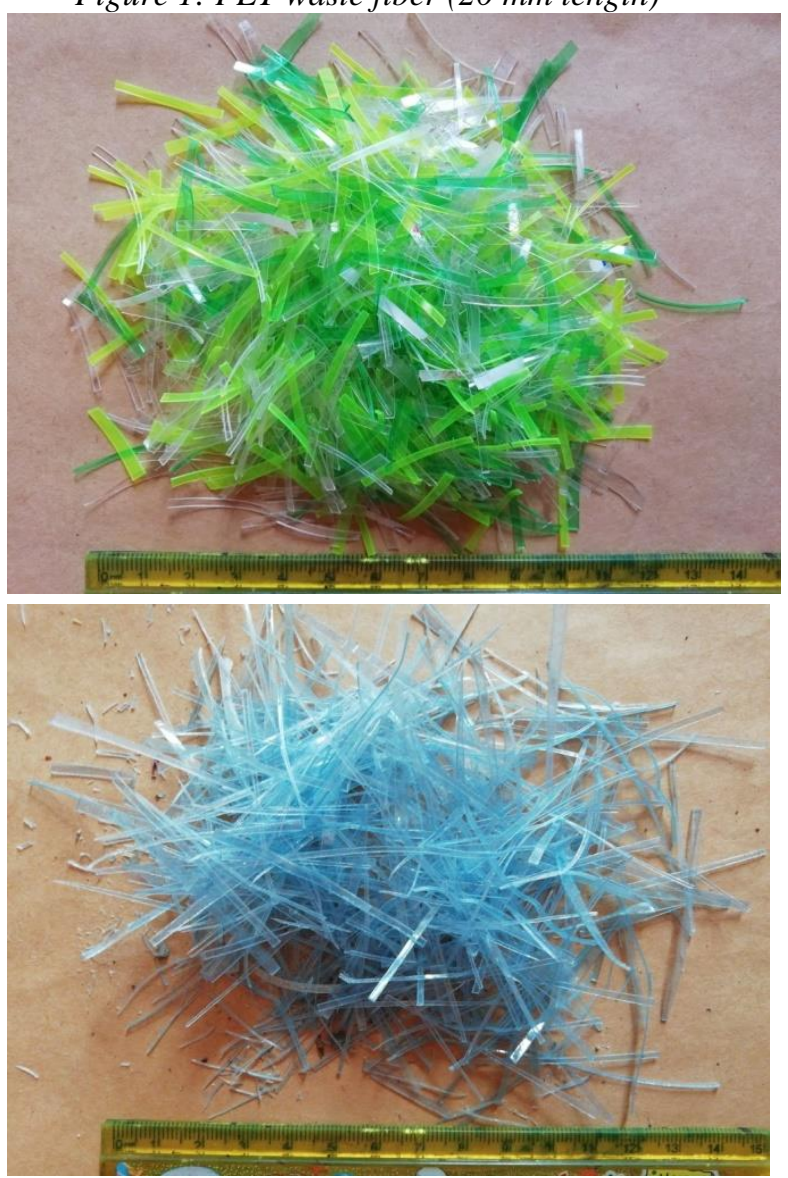

Figure 2: PET $f$ waste fiber (40 mm length)

Figure 3: PVC waste aggregate

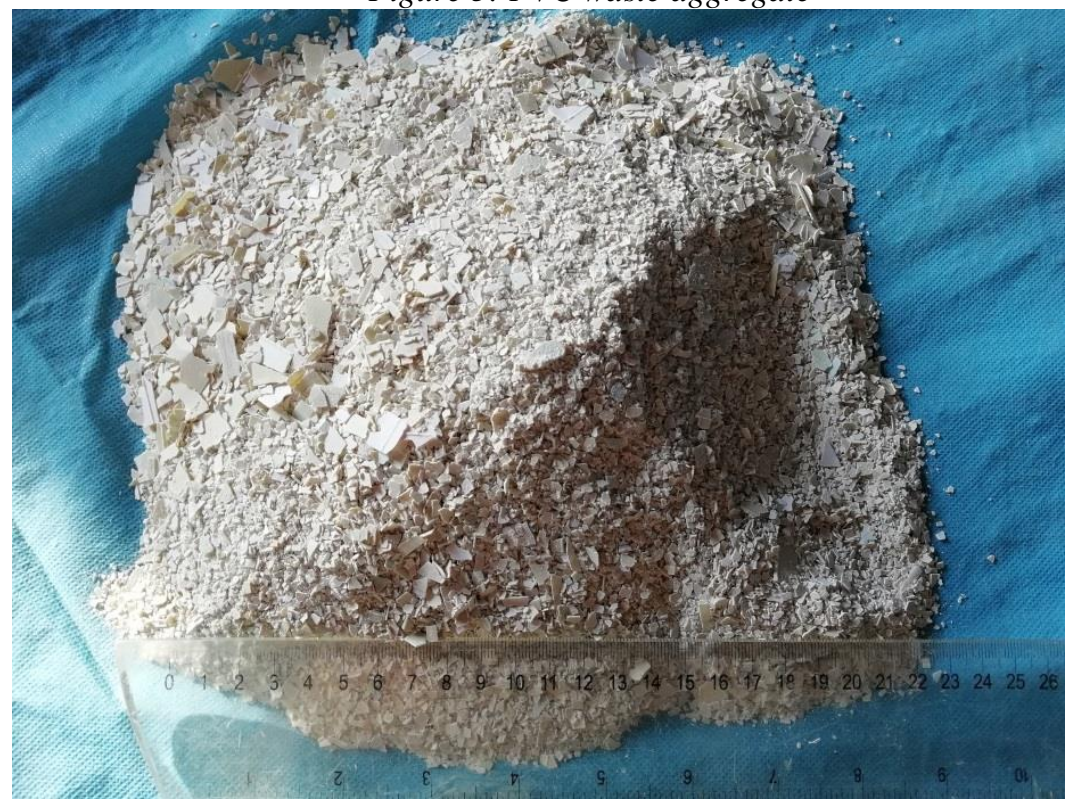




\section{$2^{\text {nd }}$ International Academic Conference on Research in}

\section{9-11 July 2021 \\ Paris, France}

\subsection{Mix proportions and mixing}

Mix proportion chosen was 1:1.25:2.5 (cement: fine aggregate: coarse aggregate (by weight)) with water/cement ratio of 0.5 , to produce a concrete mix with design compressive strength equal to $40 \mathrm{MPa}$. PET fiber was added by $0.5,0.75,1$, and $1.25 \%$ by volume to concrete, while PVC aggregate was added to concrete as fine aggregate replacement by 5,15 , 30 , and $45 \%$ by volume. Accordingly, a total of nine mixes were used for casting concrete specimens. Mixing concrete was done using a $0.16 \mathrm{~m}^{3}$ capacity electrical tilting drum. Firstly, dry materials of cement, coarse aggregate, and fine aggregate were fed into the mixer and left to rotate for two minutes. Later, water was added and the mass was allowed to mix for another three minutes till a homogeneous mixture was obtained. For concrete mixes with PET fiber, after that the mentioned steps have been finished, the plastic fiber was sprayed continuously on concrete inside the tilting drum while rotating, and this process was finished in about three minutes. With regard to concrete mix with PVC waste aggregate, firstly, weight of the constituent materials of control mix was calculated. Volume of fine aggregate was calculated based on the compacted bulk density. Ratio of PVC aggregate volume for each mix was calculated and changed to weight based on the dry density of the PVC granule. Prior to concrete casting, all inner surfaces of the molds were thoroughly oiled using lubricant oil. Specimen molds were filled with concrete and vibrated. After $24 \mathrm{~h}$ from casting, the specimen was taken from the mould and put in water tank for curing for 28 days. Later, the specimen was taken from the water tank and left in the laboratory to dry for three days before testing.

\subsection{Impact strength test setup}

To measure impact strength of concrete with or without plastic wastes, a none instrumented multiple drop-weight test was followed to determine impact strength in terms of number of blows. The procedure is, in general, based on the test method described by ACI committee 544 [13]. In this study, the modification of the ACI committee 544 [13] made by Marar et al. [14] was followed to facilitate the test procedure, mainly reducing number of blows. This method is based on changing drop weight from $4.75 \mathrm{~kg}$ given by ACI committee 544 to $13.5 \mathrm{Kg}$, and changing the drop height from $45.7 \mathrm{~cm}$ to $30 \mathrm{~cm}$. Concrete disc specimen of dimensions $(150$ $\mathrm{mm}$ diameter and $63.5 \mathrm{~mm}$ thickness) was used for all tests. Following this test procedure, number of blows causing first crack $\left(\mathrm{N}_{1}\right)$ and failure $\left(\mathrm{N}_{2}\right)$ of the specimen using visual inspection can be recorded. Fig. 4 and Fig. 5 show a schematic view and actual view of the impact test machine, respectively. 
09-11 July 2021

Paris, France

Figure 4: Schematic view of impact strength test machine.

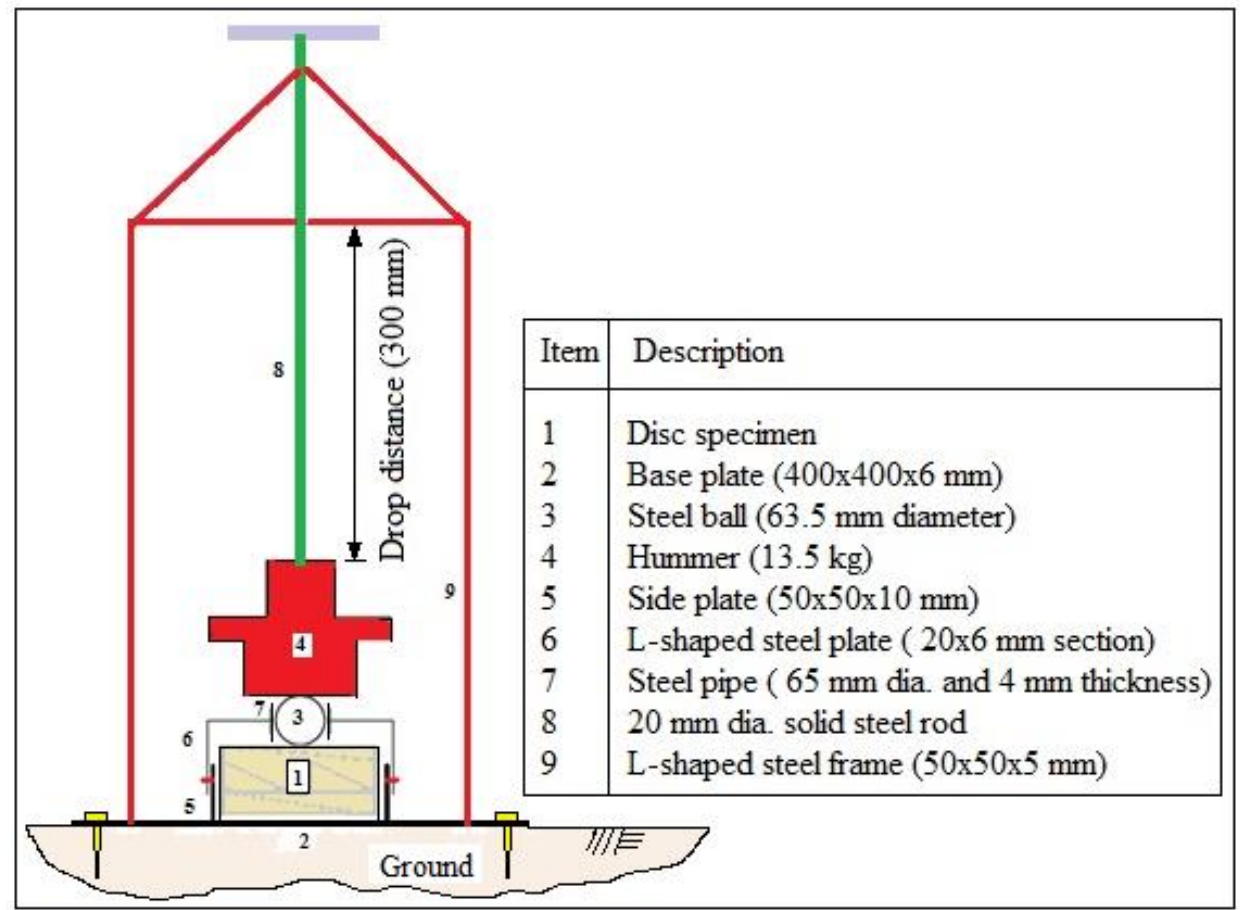




\section{$2^{\text {nd }}$ International Academic Conference on Research in}

09-11 July 2021

\section{Paris, France}

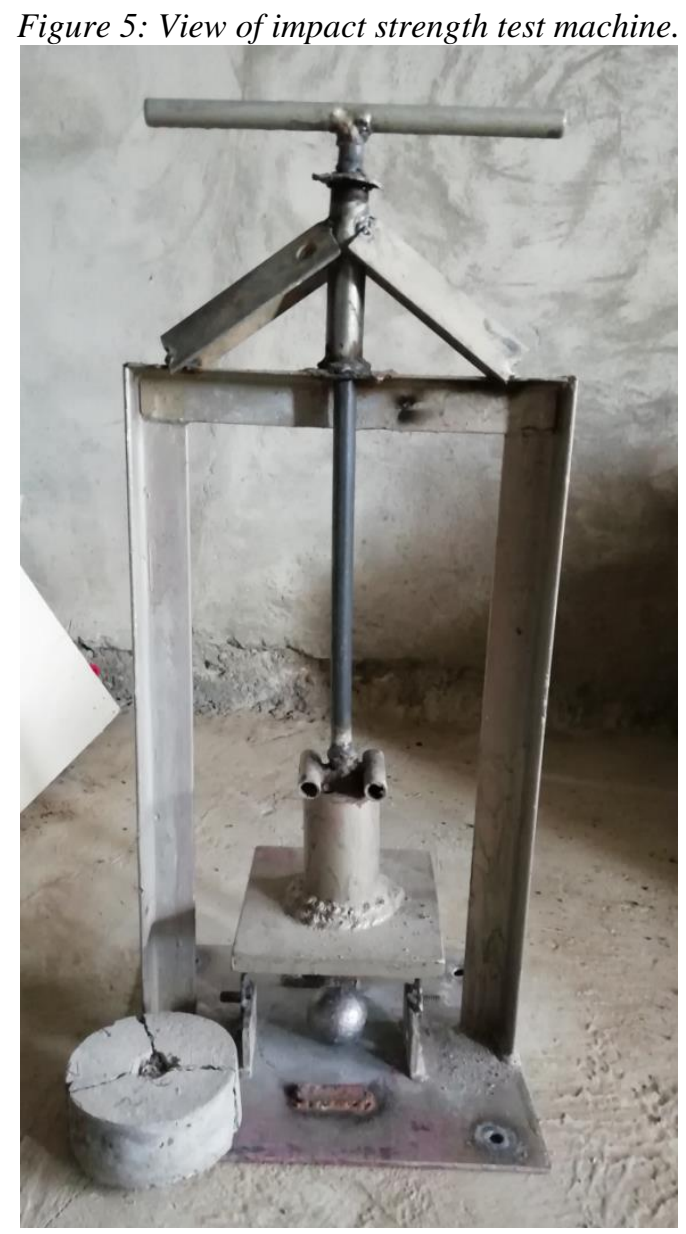

\section{Results and discussion}

\subsection{Concrete containing PET fiber}

Figure 6 shows variation of first crack impact of concrete with PET waste fiber volume. The ratios of the first crack impact are equal to $145 \%, 197 \%, 123 \%$ and $61 \%$ for $0.5 \%, 0.75 \%, 1 \%$ and $1.25 \%$ PET fiber of $20 \mathrm{~mm}$ length respectively. For $40 \mathrm{~mm}$ PET fiber, the ratios are $123 \%$, $110 \%, 48 \%$ and $68 \%$ respectively. Therefore, there is a positive influence of short PET waste fiber when added to concrete by up to $0.75 \%$, while for $40 \mathrm{~mm}$ fiber there is a chance to be added by $0.5 \%$ to enhance first crack impact. The positive influence of PET fiber may be attributed to the crack control of concrete because of the existence of distributed plastic fiber. Ochi et al. [15] reported that PET fiber has the ability to control cracking of concrete occurred because of shrinkage. From figure 6, one can observe a reduction in the first crack impact with increasing PET fiber volumes reaching a maximum value of $39 \%$ for $20 \mathrm{~mm}$ length fiber, and $52 \%$ for $40 \mathrm{~mm}$ length fiber. The reason of the first crack impact reduction is attributed to the reduction of the non-homogeneity of concrete because of a relatively high ratio of PET waste fiber. This reduction is attributed to the existence of flaws between the plastic surface and 


\section{${ }^{2 \text { nd }}$ International Academic Conference on Research in}

\section{9-11 July 2021 \\ Paris, France}

hardened concrete, able to reduce the bond between the two materials. This weak zone is a source of cracks formation and extension under the influence of impact load. The deterioration of important properties of concrete because of the existence of high ratios of PET fiber was observed experimentally $[2,10]$.

Results of ultimate load impact of tested specimens are shown in Figure 6. The ratios of the ultimate load impact are equal to $171 \%, 223 \%, 132 \%$ and $74 \%$ for $0.5 \%, 0.75 \%, 1 \%$ and $1.25 \%$ PET fiber of $20 \mathrm{~mm}$ length respectively, while for $40 \mathrm{~mm}$ PET fiber, the ratios are $155 \%, 152 \%$, $58 \%$ and $81 \%$ respectively. Therefore, there is a positive influence of short PET waste fiber when added to concrete by up to $0.75 \%$, and for $40 \mathrm{~mm}$ fiber there is a chance to be added by $0.5 \%$ as maximum ratio to enhance the ultimate load impact. One can also observe that with increasing PET fiber volume the difference between the first crack impact and ultimate load impact reduces. The results are in agreement with those obtained by Parahallada and Prakash [10], but the optimum dosage obtained by these authors is $1 \%$, slightly higher than that obtained in this study.

\subsection{Concrete containing PVC aggregate}

Figure 7 shows variation of first crack and ultimate load impacts of concrete with PVC waste aggregate content. One can observe a continuous reduction in both first crack and ultimate load impacts with increasing PVC aggregate content, being increased with increasing PVC aggregate content, reaching $84 \%$ at $45 \%$ sand replacement with the plastic. The reason behind the impact strength loss may be due to increasing flaws and cavities between hardened cement paste and PVC aggregate particles, in which cracks can be initiated from the weak transition zone and extended causing final collapse. One can observe that, in contrast to the case of concrete with PET fiber content, first crack impact and ultimate load impact are close to each other, and the difference between the two impacts is negligible for all PVC aggregate contents. It is of interest to compare the current test data with those obtained by Jain et al. [11] on impact strength of concrete contained waste plastic bag (WPB). The number of blows for the first crack and final failure was enhanced by 73.68 and $80 \%$ at an amount of 5\% WPB, respectively, while it was enhanced by 436.84 and $392 \%$ at an amount of $20 \%$ WPB content, respectively. Accordingly, there is a beneficial effect of the plastic waste addition on the impact strength, in contrast to the case of using PVC sheet aggregate used in the current study. The reason of this difference can be attributed to the effect of the plastic particles shape and thickness, in which the plastic waste used by Jain et al. [11] tends to be a plastic fiber rather than shredded fiber in the form of an aggregate, because of a relatively large length and small thickness. Figure 8 shows disc specimens after failure. In general, mode of failure is independent on the existence of PET fiber or PVC aggregate.

\subsection{Relationship between first crack impact and ultimate load impact}

It is of good interest to study the relationship between the first crack impact and ultimate load impact. For different types of concrete there is a linear relationship between the two impacts, represented by the following equation [6] 
09-11 July 2021

\section{Paris, France}

$$
\mathrm{N}_{2}=\alpha+\beta \mathrm{N}_{1}
$$

Figure 6: Variation of first crack and ultimate load impacts with PET fiber volume

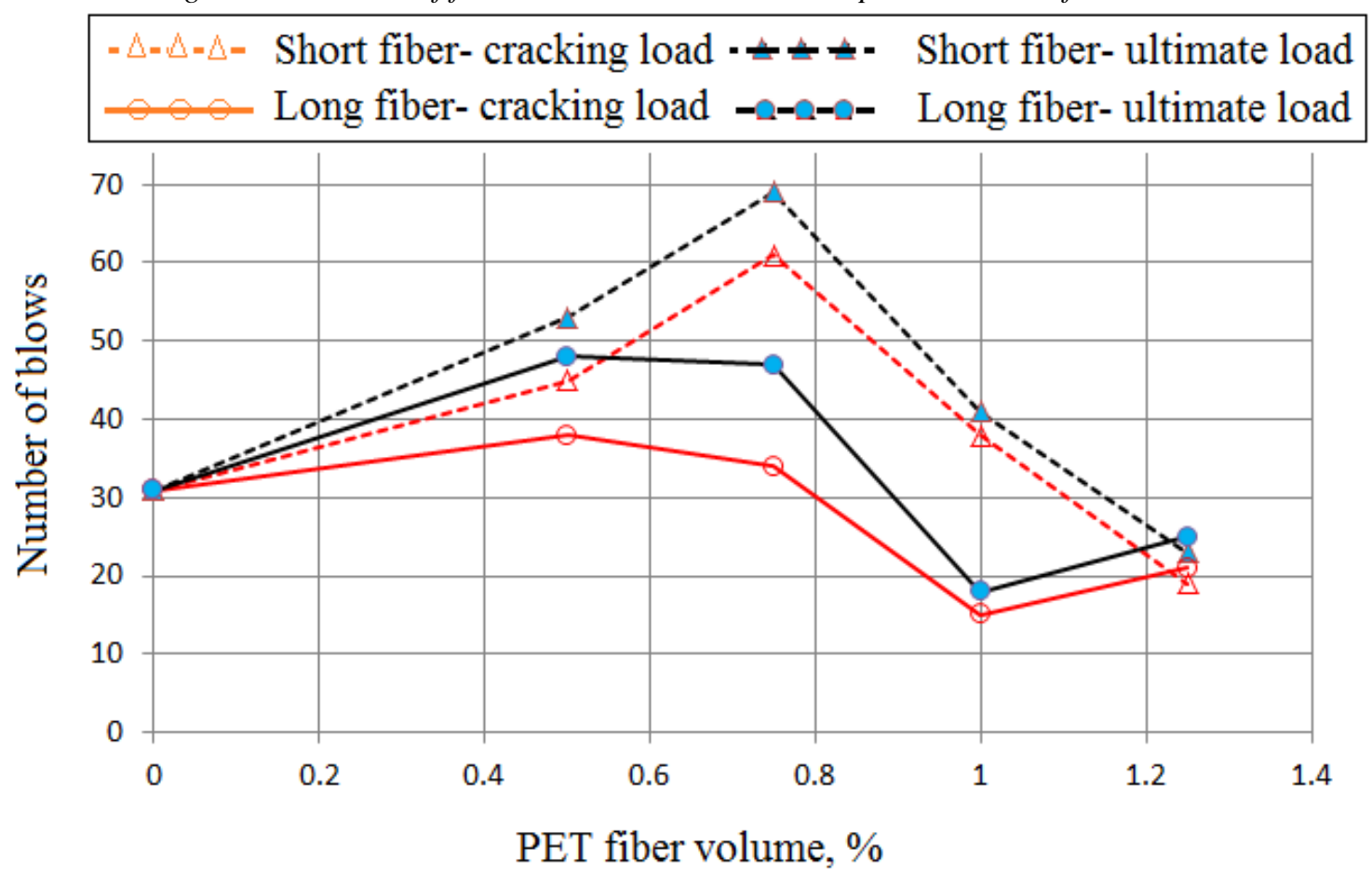

Figure 7: Variation of first crack and ultimate load impacts with PVC aggregate volume

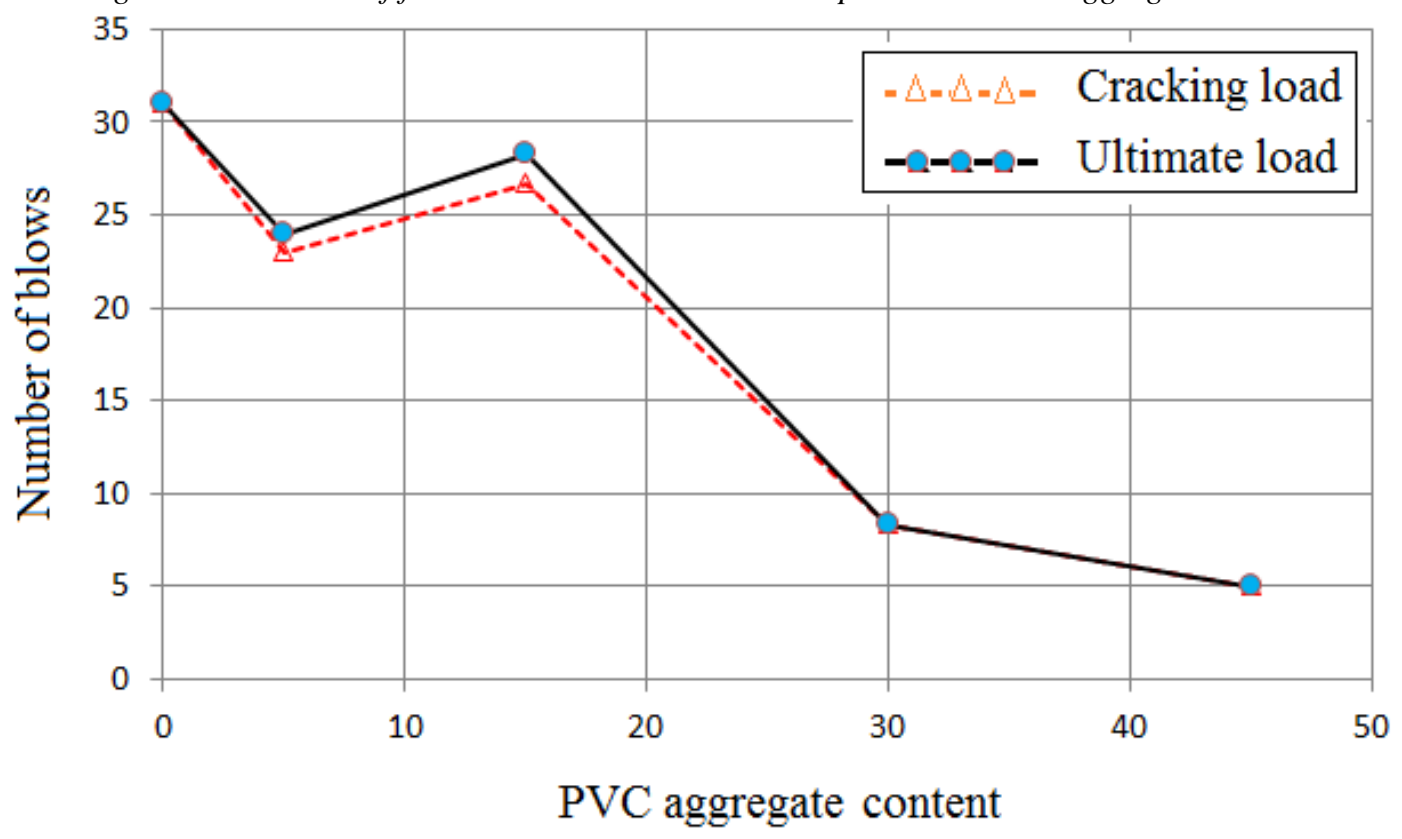

Figure 8 View of failed specimens 


\section{$2^{\text {nd }}$ International Academic Conference on Research in ENGINEERING AND TECHNOLOGY}

09-11 July 2021

\section{Paris, France}

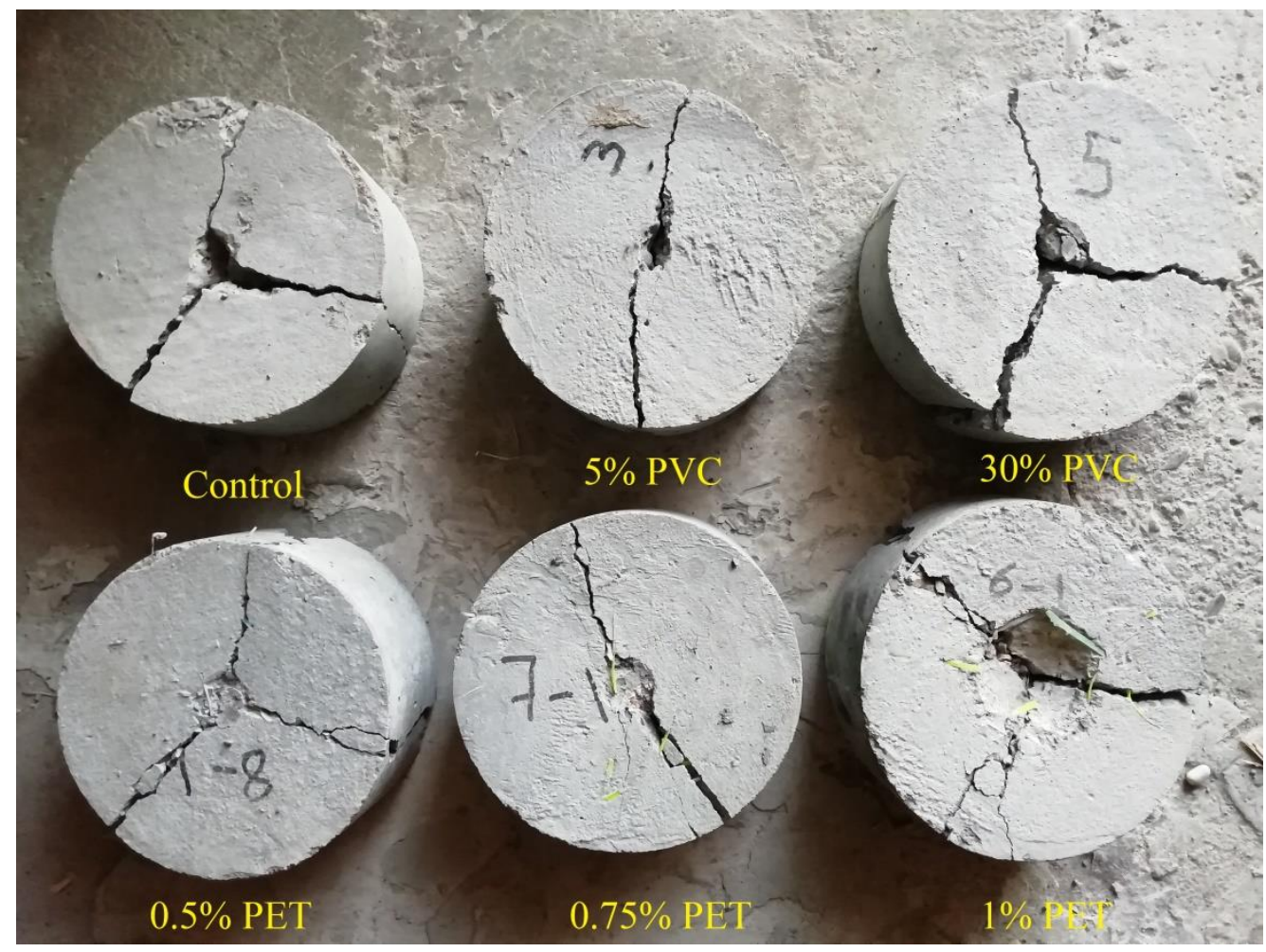

In which $\mathrm{N}_{1}$ is the first crack impact, $\mathrm{N}_{2}$ is the ultimate load impact and $\alpha$ and $\beta$ are coefficients. Figure 9 shows the relationship between $\mathrm{N}_{1}$ and $\mathrm{N}_{2}$ for the case of concrete with PET fiber and concrete with PVC aggregate. Regression analysis indicate that there is a linear relationship between the two impacts given by the following equations

For the case of concrete with PET fiber

$$
\mathrm{N}_{2}=0.7775+1.1358 \mathrm{~N}_{1}
$$

For the case of concrete with PVC aggregate

$$
\mathrm{N}_{2}=0.0822+1.0327 \mathrm{~N}_{1}
$$

The values of the coefficient of determination for the above equations are 0.94 and 0.997 respectively, from which one can observe a stronger relationship for the case of concrete with PVC aggregate. 


\section{$2^{\text {nd }}$ International Academic Conference on Research in}

\section{9-11 July 2021 \\ Paris, France}

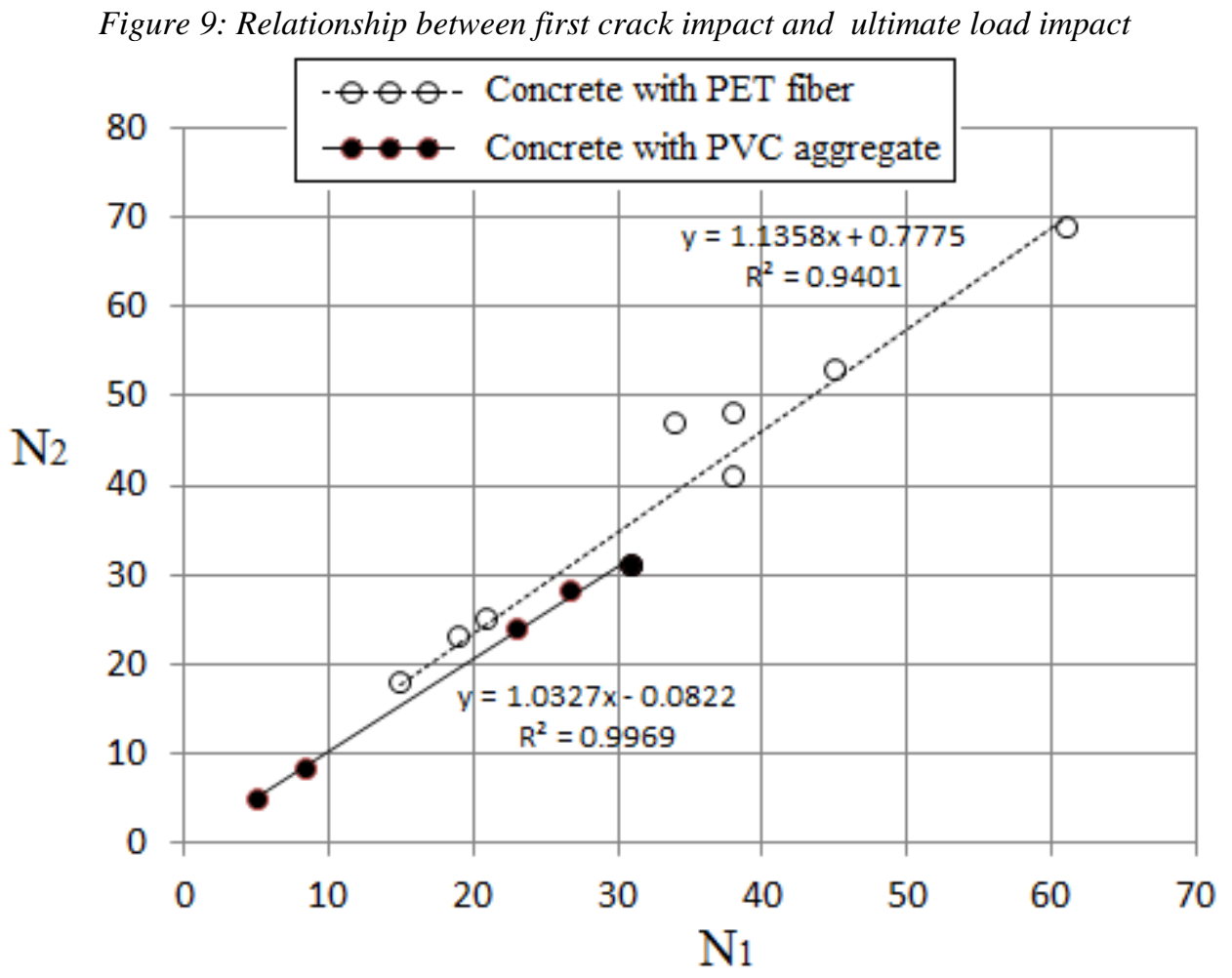

\section{Conclusions}

From the results of the research study presented in this paper, the following conclusions can be drawn

1. Addition of PET waste fiber of $20 \mathrm{~mm}$ length causes an enhancement of both first crack impact and ultimate load impact, by $97 \%$ and $123 \%$, respectively at $0.75 \%$ fiber content. For the $40 \mathrm{~mm}$ PET fiber the impact strength enhancement was found to be lower. When PET fiber is increased, there is a continuous deterioration of both impact values.

2. There is an impact strength loss of concrete as a result of PVC waste aggregate addition to concrete, being increased with increasing the dosage, reaching $84 \%$, related to using $45 \%$ PVC waste aggregate as sand replacement.

3. There is a strong linear relationship between first crack impact and ultimate load impact for concrete with PET fiber and PVC aggregate. The quality of the relation for concrete with PVC aggregate was found better.

\section{References}

[1] Mohammed, A. A. and Faqe Rahim, A. A. (2020). Experimental behaviour and analysis of high strength concrete beams reinforced with PET waste fiber, Construction and Building Materials, vol. 244, pp. 1-13. 


\section{$2^{\text {nd }}$ International Academic Conference on Research in}

\section{9-11 July 2021 \\ Paris, France}

[2] Gu, L., Ozbakkaloglu, T. (2016). Use of recycled plastics in concrete: a critical review, Waste Management, vol. 51, pp. 19-42.

[3] Siddique, R., Khatib, J., Kaur, I. (2008). Use of recycled plastic in concrete: a review, Waste Management, vol. 28, pp. 1835-1852.

[4] Bahji, S., Omary, S. Feugeas, F., Faqiri, A. (2020). Fresh and hardened properties of concrete containing different forms of plastic waste- A review, Waste Management, vol. 113, pp. 57-75.

[5] Neville, A. M., (2004). Properties of concrete, $4^{\text {th }}$ ed., Prentice Hall, pp.343.

[6] Zhu, X. , Zhu, H., Li, H. ( 2015). Drop- weight impact test on U-shape concrete specimens with statistical and regression analysis, Materials, vol. 8, pp. 5877-5890.

[7] Abhinav, K. S. and Rao, N. S. (2016). Investigation of impact resistance of steel fiber reinforced concrete, International Research Journal of Engineering and Technology (IRJET), vol. 3, pp. 954-958.

[8] Kun, Y. M. (2012). Mechanical properties and impact resistance of hybrid fiber reinforced high strength concrete, MSc thesis, University of Malaya.

[9] Karim, S. A. and Mohammed, A. A., (2019). Impact strength of concrete and testing: A critical review. Proceedings of $5^{\text {th }}$ international conference of advances in mechanical engineering. Istanbul, Turkey, pp. 956-965.

[10] Parahallada, M. C. and Prakash, K. B. Strength and workability characteristics of waste plastic fiber reinforced concrete produced from recycled aggregates, International journal of engineering research and applications (IJERA), vol. 4, pp. 1791-1802.

[11] Jain, A., Siddique, S., Gupta, T., Sharma, R. K., Chaudhary, S. (2018). Utilization of shredded waste plastic bags to improve impact and abrasion resistance of concrete, Environment, Development and Sustainability, https://doi.org/10.1007/s10668-018-02041

[12] Al-Hadithi, A. I., Noaman, A. T., Mosleh, W. K. Mechanical properties and impact behavior of PET fiber reinforced self compacting concrete (SCC), Composite Structures, vol. 224, 111021.

[13] ACI committee 544. (1988). Measurement of properties of fiber reinforced concrete, ACI Materials Journal, vol. 85, pp. 583-593.

[14] Marrar, K., Eren, Ö, Çelik, T. (2001). Relationship between impact energy and compression toughness energy of high-strength fiber-reinforced concrete, Materials Letters, vol. 47, pp. 297-304.

[15] Ochi, T., Okubo, S., Fukui, K. (2007). Development of recycled PET fiber and its application as concrete-reinforcing fiber, Cement and Concrete Composites, vol. 29, pp. $448-455$. 